\title{
Adult-type Granulosa Cell Ovarian Tumor: Clinicopathological Features, Outcomes, and Prognostic Factors
}

\author{
Amornrat Temtanakitpaisan, Pilaiwan Kleebkaow, Apiwat Aue-aungkul
}

Department of Obstetrics and Gynaecology, Faculty of Medicine, Khon Kaen University, Khon Kaen, Thailand.

\begin{abstract}
Objective: To evaluate the clinicopathological features, outcomes and prognostic factors affecting the disease-free interval in women with adult-type granulosa cell tumor. Methods: A retrospective descriptive study of patients with adult-type granulosa cell tumors of the ovary (AGCTs) during January 2001 to October 2016 were recruited. The data record of all patients was analyzed to determine clinic-pathological features, treatment, survival, and prognostic factors. Results: Eighteen women with adult-type granulosa cell tumors (AGCTs) were diagnosed. The mean age + SD was $48.72+5.95$ years. The adnexal mass was the most common presenting symptoms $(83.3 \%)$ and most were diagnosed in FIGO stage I (83.3\%). The majority of patients $(55.6 \%)$ were treated with complete staging surgery. Additionally, $22.2 \%$ were given postoperative chemotherapy. Endometrial cancer was detected in only one case. The mean follow-up period $+\mathrm{SD}$ was $43.11+26.02$ months. No recurrence of disease was observed in all patients. The estimated 5-year disease-free survival (DFS) was $95 \%$ regardless of the stage of the disease. The stage disease slightly influenced disease-free survival. However, no statistical difference between stages $(p=0.52)$. No prognostic factors associated with DFS significantly. Conclusion: The majority of the patients with adult-type granulosa cell tumors of the ovary (AGCTs) presented in the early stage of disease and have an excellent survival rate. Tumor removal procedure with or without complete staging surgery seemed to be the appropriate treatment for granulosa cell tumors. No prognostic factors affecting on disease-free survival rate was found.
\end{abstract}

Keywords: Adult-type granulosa cell ovarian tumor- outcome- prognostic factors

Asian Pac J Cancer Care, 4 (2), 33-37

\section{Introduction}

Granulosa cell tumors of the ovary (GCTs) was first described by Rokitansky [1], are uncommon neoplasm representing $3-5 \%$ of all ovarian tumors [2]. Implied meaning that GCT is derived from the granulosa cell which is a hormonally active cell of the ovarian stroma responsible for estradiol production. GCT is therefore referred to as an ovarian sex cord-stromal tumor, it accounts for $70 \%$ of the tumors in this group.

GCTs are divided into an adult (AGCT) and juvenile (JGCT) types based on differences in clinical and histopathologic features. AGCTs are commonly seen in perimenopausal and postmenopausal women. A peak incidence is 50-55 years. The prognostic of these tumors is good when comparing with other epithelial tumors [3]. Endometrial hyperplasia of the endometrium is an adverse consequence of excessive hormone production. Moreover,
Submission Date: 12/09/2018 Acceptance Date: 02/05/2019

some reported the association with endometrial carcinoma [4]. Conversely, JGCTs are rare tumors. It is approximately $5 \%$ of all GCTs and occurring in premenarchal girls and young women [5]. Patients with juvenile GCT typically present at an early stage with a favorable prognosis. While those presenting with the advanced-stage disease might experience an aggressive clinical presentation.

Recurrence of GCTs tends to occur in indolent fashion even in the early-stage disease [5]. It takes approximately 5 to 30 years after initial diagnosis [4]. However, there are limited data regarding predisposing risks, prognostic factors with an adequate number of patients and a sufficiently long follow-up period. Therefore, the aims of the study were to evaluate the clinical presentation, pathological features, treatment, and determine the prognostic factors affecting the disease-free interval of patients with the adult type granulosa cell tumor.

Corresponding Author:

Amornrat Temtanakitpaisan

Department of Obstetrics and Gynaecology, Faculty of Medicine, Khon Kaen University, Khon Kaen, Thailand.

Email: kunglekmed@hotmail.com 


\section{Materials and Methods}

A retrospective descriptive study was performed at Srinagarind Hospital by reviewed outpatient(OPD) medical records and computerized medical records after approval from The Khon Kaen University Ethics Committee in Human Research. The patients with adult-type granulosa cell ovarian tumor on histopathological report who have undergone surgery in Srinagarind Hospital between January 2001 and October 2016 were recruited.

Patient characteristics, clinical presentation, pathological reports, the extent of surgery, postoperative adjuvant therapy, recurrence, and follow-up status were collected. The disease-free interval defined as the time from the date of initial operation to the date of recurrence or the date of the last follow-up was determined.

The histopathological results were re-evaluated and interpreted by only one gynecologic pathologist of Srinagarind Hospital (K.Pilaiwan).

Statistical analysis was performed using SPSS version 22.0. The Kaplan-Meier method was used to assess the disease-free interval, and multivariate analyses were performed using the Cox regression model. A p-value of $<0.05$ was considered to be statistically significant.

\section{Results}

Eighteen adult-type granulosa cell tumors (AGCTs) patients were recruited. The mean age+ SD was $48.72+$ 13.54 years. Ten patients $(55.6 \%)$ were in premenopausal status and 12 patients $(66.7 \%)$ were multi-parity. The most common leading symptoms were adnexal mass followed by abnormal vaginal bleeding, abdominal pain and GI symptoms. There were $83.3 \%, 44.4 \%, 38.9 \%$ and $33.3 \%$, respectively. Serum CA-125 was measured preoperatively in 12 patients. The mean $+\mathrm{SD}$ of serum CA125 was $147.58+289.35 \mathrm{IU} / \mathrm{mL}$ (range $9.0-1006.0 \mathrm{IU} / \mathrm{mL}$, $\mathrm{SD}=289.35)$. Five patients (41.7\%) had an elevated level $(>35 \mathrm{IU} / \mathrm{mL})$ as showed in Table 1.

Regarding tumor characteristics, the mean + SD of the diameter of the ovarian mass was $12.78+5.95 \mathrm{~cm}$. Twelve patients $(66.7 \%)$ had the tumor size larger or equal than $10 \mathrm{~cm}$. The most tumor was located on the right side (55.6\%). Fourteen patients (77.8\%) presenting with early-stage disease. While 4 patients $(22.2 \%)$ had the advanced stage at the time of diagnosis as showed in Table 2.

Eleven patients $(61.1 \%)$ had characteristics of unopposed estrogen of endometrial specimens as showed in Table 3. These illustrated 7 patients $(38.9 \%)$ had endometrial proliferative phase, 3 patients $(16.7 \%)$ had endometrial hyperplasia and only one patient $(5.6 \%)$ had endometrial cancer. According to the pathological report of the tumor, 5 patients $(27.8 \%)$ had tumor infarction. In addition, 3 patients (16.7\%) had mitotic index more than 10/10 high power field (HPF).

All cases were undergone surgical treatment with 10 patients $(55.6 \%)$ underwent complete surgical staging including total abdominal hysterectomy, bilateral salpingo-oophorectomy, infracolic omentectomy,

Table 1. Clinical Characteristic of the Patients with AGCT According to Time of Diagnosis

\begin{tabular}{lcc}
\hline Characteristic $($ Total N=18 ) & Number & $\%$ \\
\hline Age at diagnosis & & $\mathrm{SD}=13.54$ \\
$\cdot$ Median (mean) & 43.39 & 55.6 \\
Menopausal status & 10 & 44.4 \\
$\cdot$ Premenopausal & 8 & 33.3 \\
$\cdot$ Postmenopausal & & 66.7 \\
Parity & 6 & 16.7 \\
$\cdot$ Nulliparous & 12 & 5.6 \\
$\cdot$ Multiparous & & 5.6 \\
Underlying disease & 3 & 83.3 \\
$\cdot$ DM & 1 & 44.4 \\
$\cdot$ Hypertension & 1 & 33.3 \\
·Heart & & 38.9 \\
Initial symptoms & 15 & 0
\end{tabular}


Table 2. Primary Tumor Characteristics of the Patients with AGCT According to Time of Diagnosis

\begin{tabular}{lcc}
\hline Characteristics & Number $(\mathrm{N})$ & $\%$ \\
\hline Tumor size $(\mathrm{cm})$. & & \\
$\cdot$ Mean (range, $3-20 \mathrm{~cm})$ & 12.78 & SD 5.95 \\
$\cdot<10 \mathrm{~cm}$. & 6 & 33.3 \\
$\cdot \geq 10 \mathrm{~cm}$. & 12 & 66.7 \\
Tumor location & & \\
$\cdot$ Right ovary & 10 & 55.6 \\
$\cdot$ Left ovary & 5 & 27.8 \\
$\cdot$ Bilateral & 1 & 5.6 \\
$\cdot$ unknown & 2 & 11.1 \\
Stage & & \\
$\cdot$ Early stage ( I ) & 14 & 77.8 \\
$\cdot$ Advanced stage (II - IV) & 4 & 22.2 \\
\hline
\end{tabular}

pelvic lymphadenectomy with or without para-aortic lymphadenectomy. Conservative surgical approaches including 6 patients $(33.3 \%)$ with unilateral oophorectomy as well as 2 patients $(11.1 \%)$ with total abdominal hysterectomy with bilateral salpingo-oophorectomy were performed. One patient (5.6\%) with advanced stage had residual tumor after surgical operation. Although in the advanced stage, chemotherapy was not injected due to poor performance status. Two patients $(11.1 \%)$ in the early stage and 2 patients $(11.1 \%)$ in the advanced stage were given chemotherapy injection after surgery as showed in Table 4.

Postoperative chemotherapy was administered in 4 patients $(22.2 \%)$. The regimens include bleomycin, etoposide, and cisplatin (BEP) in 2 patients $(11.1 \%)$ and paclitaxel and carboplatin in 2 patients $(11.1 \%)$.

The mean follow-up period was 43.11 months (range, 6 to 86 months). No recurrence was observed

Table 3. Histopathological Characteristics of the Patients with AGCT According to Time of Diagnosis

\begin{tabular}{|c|c|c|}
\hline Characteristics & $\begin{array}{c}\text { Number } \\
\text { (N) }\end{array}$ & $\%$ \\
\hline \multicolumn{3}{|l|}{ Endometrial pathology } \\
\hline No pathology & 7 & 38.9 \\
\hline Endometrial proliferative disorder & 7 & 38.9 \\
\hline Endometrial hyperplasia & 3 & 16.7 \\
\hline -Endometrial cancer & 1 & 5.6 \\
\hline \multicolumn{3}{|l|}{ Infraction } \\
\hline -Absent & 13 & 72.2 \\
\hline$\cdot$ Present & 5 & 27.8 \\
\hline \multicolumn{3}{|l|}{ Mitosis } \\
\hline -Absent & 1 & 5.6 \\
\hline -Less than $3 / 10 \mathrm{HPF}^{*}$ & 8 & 44.4 \\
\hline$\cdot 3-5 / 10 \mathrm{HPF}^{*}$ & 4 & 22.2 \\
\hline$\cdot 6-10 / 10 \mathrm{HPF}^{*}$ & 2 & 11.1 \\
\hline -More than $10 / 10 \mathrm{HPF}^{*}$ & 3 & 16.7 \\
\hline
\end{tabular}

in all patients. The 5-year disease-free survival rate was $95 \%$. The stage disease slightly influenced disease-free survival. It means that the 5-year disease-free survival rate was dropped to $75 \%$ in advanced stage disease whereas the 5-year disease-free survival was $100 \%$ in the early stage. However, no statistical difference between stages $(\mathrm{p}=0.52)$. In the univariate analysis, no prognostic factor showed associated with survival rate as showed in Table 5.

\section{Discussion}

Granulosa cell tumors of the ovary are one type of ovarian cancer that infrequently found [6]. The clinical presentation depends on the ability of the tissue to generate estrogen [7]. There are two distinct clinicopathologic subtypes like the adult and juvenile cell types. The previous study reported that adult variant is commonest, approximately $95 \%$ occurring in postmenopausal women [2]. Whereas in our study, most patients $(55.6 \%)$ were premenopausal status.

Bompas E et al. [8] reported that the most common presenting symptoms are abdominal pain and abdominal distension related to mass effect. Abnormal uterine bleeding such as irregular menstruation, intermenstrual bleeding, postmenopausal bleeding or amenorrhea is also frequently seen in these women as the result of the hormonally active tumor that leads to unopposed estrogen [8]. While in our study found that the most common presenting symptoms were adnexal mass $(3 \%)$ followed by abnormal vaginal bleeding $(44.4 \%)$, abdominal pain (38.9\%) and GI symptoms (33.3\%).

According to endometrial abnormalities, it was reported that the incidence of endometrial hyperplasia from $32-85 \%$ and endometrial carcinoma ranges from $3-22 \%(9)$. While our study showed the comparatively low rate of endometrial hyperplasia (16.7\%) and endometrial cancer $(5.6 \%)$. It might be from the increased awareness of premenopausal women more than postmenopausal women regarding abnormal menstruation. However, endometrial sampling should be sorted to rule out endometrial carcinoma particularly in women with abnormal uterine bleeding and in whom that desired fertility need.

Hysterectomy with bilateral salpingo-oophorectomy is the mainstay of treatment while the conservative measure is preserved in whom fertility function is needed. Recently, pelvic lymphadenectomy with or without para-aortic lymphadenectomy is controversial [10]. In our study, 55.6 $\%$ of patients underwent complete staging surgery and $11.1 \%$ of patients underwent a hysterectomy and bilateral salpingo-oophorectomy. Furthermore, disease-free survival between two types of surgery was not shown statistically significant.

There are controversial issues regard to prognostic factors affecting disease-free survival, certain noted that the stage was the most important prognostic factor in most studies [11]. Ahyan et al. [12] reported that the recurrence rate of granulosa cell tumor was $5.4 \%$ of stage I, $21 \%$ of stage II and $40 \%$ of stage III. While our study showed the stage was not the factor affecting disease-free survival. Moreover, the five-year disease-free survival rates were 
Table 4. Treatment Characteristics of Primary AGCT According to Time of Diagnosis

\begin{tabular}{lcc}
\hline Treatment & Number of patients & $\%$ \\
\hline Surgery & 10 & 55.6 \\
$\cdot$ Complete staging surgery & 6 & 33.3 \\
$\cdot$ Unilateral SO & 2 & 11.1 \\
$\cdot$ TAH + BSO & 3 & 16.7 \\
$\quad \cdot$ Appendectomy & & 5.6 \\
Residual tumor & 1 & 94.4 \\
$\cdot$ Yes & 17 & 77.8 \\
$\quad$ No & & 22.2 \\
Treatment modality & 14 & 11.1 \\
$\quad$ Surgery only & 4 & 11.1 \\
$\quad$ Surgery and chemotherapy & & 2 \\
Chemotherapy regimens & 2 & \\
$\quad$ BEP (Bleomycin+Etoposide+Cisplatin) & 2 & \\
$\quad$ Paclitaxel carboplatin & & \\
\hline
\end{tabular}

Table 5. Univariate Analyses of Risk Factor in AGCT-specific Survival

\begin{tabular}{|c|c|c|c|}
\hline Risk factors & Hazard ratio & $95 \% \mathrm{CI}$ & P-value \\
\hline \multicolumn{4}{|l|}{ Age (years) } \\
\hline$\cdot<60$ & Reference category & & \\
\hline$\cdot \geq 60$ & 0.04 & $0-3.33$ & 0.80 \\
\hline \multicolumn{4}{|l|}{ Tumor size } \\
\hline$\cdot<10 \mathrm{~cm}$ & Reference category & & \\
\hline$\cdot \geq 10 \mathrm{~cm}$ & 46.22 & $0-715497465.0$ & 0.65 \\
\hline \multicolumn{4}{|l|}{ FIGO stage } \\
\hline ·Early stage (I) & Reference category & & \\
\hline -Advanced stage (II-IV) & 1.53 & $0.42-5.53$ & 0.52 \\
\hline \multicolumn{4}{|l|}{ Residual tumor } \\
\hline -Absent & Reference category & & \\
\hline$\cdot$ Present & 1.00 & $0.02-50.84$ & 1.0 \\
\hline \multicolumn{4}{|l|}{ Infraction } \\
\hline -Absent & Reference category & & \\
\hline$\cdot$ Present & 0.89 & $0.31-2.62$ & 0.84 \\
\hline \multicolumn{4}{|l|}{ Mitosis } \\
\hline$\cdot £ 10 / \mathrm{HPF}$ & Reference category & & \\
\hline$\cdot>10 / \mathrm{HPF}$ & 0.04 & $0-49886023.00$ & 0.76 \\
\hline
\end{tabular}

95\% for AGCTs as well as no recurrence of disease during 5 years.

The effect of age on prognosis has also been controversial. The age less than 40 years was preferably associated with better prognosis [10]. The previous study illustrated that age less than 50 years was an independent prognostic factor for improved survival (HR, 0.217; $95 \% \mathrm{CI}, 0.067$ to 0.706 ) [13], and those whose age less than 50 years had a $10 \%$ survival advantage [14]. Furthermore, another study reported that patients aged 60 years and less had longer survival times (154.5 vs. 89.2 months, $\mathrm{p}=0.015)$ and experienced less mortality ( $4.9 \%$ vs. $21.1 \%, p=0.05)$. However, no statistically significant data regarding age on prognostic factor in multivariate analysis [12]. In our study reported that age less than 60 years was not associated with disease-free survival rate and recurrence rate.

The larger tumor size of more than $10 \mathrm{~cm}$. in diameter was associated with a poor prognosis [13]. Miller BE et al. [15] found that the recurrence was more significant with larger tumor size $(13.5 \mathrm{~cm}$ vs. $10 \mathrm{~cm}$; $=0.029)$. However, Sehouli et al. [10] reported that biological behavior influenced the aggressiveness of disease even in the smaller tumor. Moreover, other studies were unable to identify the prognostic significance of tumor size [16]. Our study showed no statistical differences in disease-free survival based on tumor size.

Residual tumor after surgery is also another prognosis 
factor. Al-Badawi et al. [17] reported that survival rate was significantly lower for patients with the postoperative residual disease. In our study found that only one patient $(5.6 \%)$ with residual lesions and no recurrence disease. Therefore, residual tumor was not a statistically significant difference in disease-free survival.

The number of mitoses characterized a prognostic factor and inversely related to survival and the number of mitoses [10-11]. In our study found that no relationship between the number of mitotic figures and survival rate.

This is a retrospective study to evaluate the clinicopathological features, outcomes and prognostic factors affecting the disease-free interval in women with granulosa cell tumor with only one gynecologic pathologist interpreted all accordingly this is the strength of the study. The limitation of our study was the retrospective study with small sample size. However, due to the rarity of these tumors, it is difficult to conduct a prospective study in one institute. Therefore, multicenter prospective data might sound promising.

In conclusion, the majority of the patients with adult-type granulosa cell tumors of the ovary (AGCTs) presented in the early stage and have excellent survival outcomes. Primary surgical treatments seemed to be the appropriate treatment for granulosa cell tumors. In our study, no prognostic factors affecting disease-free survival rate was found. Diligent endometrial pathology has been sorted to rule out endometrial carcinoma which helps in its early detection.

\section{Funding Statement \\ None}

\section{References}

1. Rokitansky C. Uber abnormalitiaten des corpus luteum. Allg Wien Med Z.1895;4:235-8.

2. Schweppe KW, Beller FK. Clinical data of granulosa cell tumors. Journal of cancer research and clinical oncology. 1982;104(1-2):161-9.

3. Sekkate S, Kairouani M, Serji B, Tazi A, Mrabti H, Boutayeb $\mathrm{S}$, et al. Ovarian granulosa cell tumors: a retrospective study of 27 cases and a review of the literature. World journal of surgical oncology. 2013;11:142.

4. Malmstrom H, Hogberg T, Risberg B, Simonsen E. Granulosa cell tumors of the ovary: prognostic factors and outcome. Gynecologic oncology. 1994;52(1):50-5.

5. Powell JL, Johnson NA, Bailey CL, Otis CN. Management of advanced juvenile granulosa cell tumor of the ovary. Gynecologic oncology. 1993;48(1):119-23.

6. Schumer ST, Cannistra SA. Granulosa cell tumor of the ovary. Journal of clinical oncology : official journal of the American Society of Clinical Oncology. 2003;21(6):1180-9.

7. McNatty KP, Makris A, DeGrazia C, Osathanondh R, Ryan KJ. The production of progesterone, androgens, and estrogens by granulosa cells, thecal tissue, and stromal tissue from human ovaries in vitro. The Journal of clinical endocrinology and metabolism. 1979;49(5):687-99.

8. Bompas E, Freyer G, Vitrey D, Trillet-Lenoir V. [Granulosa cell tumour: review of the literature]. Bulletin du cancer. 2000;87(10):709-14

9. Pautier P, Lhomme C, Culine S, Duvillard P, Michel G,
Bidart JM, et al. Adult granulosa-cell tumor of the ovary: a retrospective study of 45 cases. International journal of gynecological cancer : official journal of the International Gynecological Cancer Society. 1997;7(1):58-65.

10. Sehouli J, Drescher FS, Mustea A, Elling D, Friedmann W, Kuhn W, et al. Granulosa cell tumor of the ovary: 10 years follow-up data of 65 patients. Anticancer research. 2004;24(2c):1223-9.

11. Fujimoto T, Sakuragi N, Okuyama K, Fujino T, Yamashita $\mathrm{K}$, Yamashiro S, et al. Histopathological prognostic factors of adult granulosa cell tumors of the ovary. Acta obstetricia et gynecologica Scandinavica. 2001;80(11):1069-74.

12. Ayhan A, Salman MC, Velipasaoglu M, Sakinci M, Yuce K. Prognostic factors in adult granulosa cell tumors of the ovary: a retrospective analysis of 80 cases. Journal of gynecologic oncology. 2009;20(3):158-63.

13. Chan JK, Zhang M, Kaleb V, Loizzi V, Benjamin J, Vasilev $\mathrm{S}$, et al. Prognostic factors responsible for survival in sex cord stromal tumors of the ovary--a multivariate analysis. Gynecologic oncology. 2005;96(1):204-9.

14. Zhang M, Cheung MK, Shin JY, Kapp DS, Husain A, Teng $\mathrm{NN}$, et al. Prognostic factors responsible for survival in sex cord stromal tumors of the ovary--an analysis of 376 women. Gynecologic oncology. 2007;104(2):396-400.

15. Miller BE, Barron BA, Wan JY, Delmore JE, Silva EG, Gershenson DM. Prognostic factors in adult granulosa cell tumor of the ovary. Cancer. 1997;79(10):1951-5.

16. Bjorkholm E, Silfversward C. Prognostic factors in granulosacell tumors. Gynecologic oncology. 1981;11(3):261-74.

17. Al-Badawi IA, Brasher PM, Ghatage P, Nation JG, Schepansky A, Stuart GC. Postoperative chemotherapy in advanced ovarian granulosa cell tumors. International journal of gynecological cancer : official journal of the International Gynecological Cancer Society. 2002;12(1):119-23.

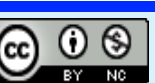

This work is licensed under a Creative Commons AttributionNon Commercial 4.0 International License. 